\title{
The Association between serum protein electrophoresis patterns and severity of patients infected with SARS-CoV-2 virus
}

\author{
*Ammar Kamal Jaafar \\ ***Mohammed A. M. Ali Albayati \\ ***Ahmed AboodAlmaliky \\ *,** /Al-Nahrain University / College of Medicine / Department of Chemistry and Biochemistry / \\ Iraq \\ ***/ The Specialized Center for Endocrinology and Diabetes. Health Directorate of Baghdad, \\ MOH, Iraq. \\ E-mail / mustafasaleam@yahoo.com \\ Mobile / +9647725503941
}

\begin{abstract}
Background :-The Coronavirus epidemic 2019 (COVID-19) is really a highly infectious sickness that is causing a huge danger to human life throughout the world. The induction of acute cytokine storm and immunosuppressive in COVID19 patients causes a rise in cytokines levels in the blood. Furthermore, the full extent of serum protein alterations in COVID-19 patients remains unclear.

Patients and methods: -In a cross-sectional study, 80 SARS-CoV-2 virus-infected patients aged 18 to 80 were categorized according to severity of infection and their serum protein electrophoresis assessment in relation to the severity of Covid-19.

Results :-SPE for patients infected with SARS-CoV-2 virus showeda significant differences in albumin, beta and gammaand there was no significant relation with the $\alpha 1$ and $\alpha 2$ all in comparison between the subgroups themselves .

Conclusion :-we conclude from the finding :albumin, beta and gamma fractions showed decrease in levels In conjunction with disease severity.

Key words :- Serum Protein Electrophoresis SPE, Alpha 1, Alpha 2, Beta, Gamma, SARS-CoV-2,COVID-19.
\end{abstract}




\section{Introduction}

In December 2019, the novel coronavirus 2 provoked severe acute respiratory syndrome in Wuhan, China. Cytokine release syndrome and multiple organ failure are two complications of the illness that, if severe enough, can lead to organ failure and death [1][2].Many academic and clinical studies across the world have looked at different signs of Covid-19 infection and their relationship to illness severity and progress, including haematological, biochemical, inflammatory, and coagulation biomarkers [3]. Proteins are the most widespread and abundant component of blood serum or plasma, and they play a vital role in a integer of physiological processes[4]. Any dysfunction and imbalance in their quantities might cause or result in disease processes [5].

Acute phase proteins APPsare inflammation indicators that show greatdifferences in serum concentration during the inflammatory response accompanied SARSCoV-2 infection [6].Serum protein Electrophoresis (SPE) is an electrophoretic technique used to isolate proteins found in the serum into dissimilar fractions depending on their molecular weight and electrical charges to , Albumin, alpha 1, alpha 2, beta, and gamma are the main portions. SPE has been usually used in clinical medicine to help identify numerous clinical disorders such as acute and chronic inflammation, monoclonal gammopathy, nephropathy, and liver disease [7].

Analyzing the serum protein components of COVID-19 patients might provide insight into how the body reacts to SARS-CoV-2 infection, which could have a big influence on the COVID-19 vaccine [8]. Further research into the protein profile might assist in the study of COVID-19 pathogenesis and the discovery of effective therapies[9].SPE is analysed in relation to severity inthis study are determined in patients who are confirmed for SARS-CoV-2.

\section{Material and Methods}

In a cross-sectional study, 80 patients aged 18 to 80, (40 males and 40 females) infected with SARS-CoV-2 virus as evidenced by a positive nasal or throat swab of RT-PCR were used and divided into three categories related to disease severity according to COVID-19 Clinical management: living guidance [10]The research was carried out at Al-Kindi Teaching Hospital in Baghdad, Iraq's capital, from November 1st, 2020 until May 1st, 2021. After obtaining verbal agreement, patients who fulfilled the criteria were enrolled in the study, Exclusion criteria include a history of nephrotic syndrome or proteinuria, as well as liver cirrhosis, pregnancy, and use of amino acid supplements.

Patients' veins yielded around $5 \mathrm{ml}$ of blood were placed in a serum separator tube . Using the proper method, measurements SPE analysis with the SAS-1+ and SAS2 automated electrophoresis analyzer/processor systems [11]. 
The goal was to examine SPE profiles in association to the severity of SARSCoV2 positive individuals.

Statistical analysis

The data were analyzed using the Statistical Package for Social Sciences (SPSS) version 22.0. The descriptive statistics, such as frequency, mean, and standard deviation, were calculated. The groups were compared using analysis of variance (ANOVA), while the degree of association between continuous variables was calculated using Pearson's correlation coefficient (r), and the results were considered statistically significant when the p value was less than 0.05.

\section{Results}

Eighty patients (40 male) and (40 female) divided into three groups according to the severity; moderate : 26 , severe : 25 , critical : 29 .

In table (1) and figure (1) the comparison of SPE parameters between the subgroups themselves and results showed a significant differences in albumin $(p<$ $0.001), \beta(p<0.001), \gamma(p=0.02)$. Moreover, there was no significant relation with the $\alpha$ Table (1): comparison of SPE parameters between study groups

\begin{tabular}{llll}
\hline patterns & Group & $\begin{array}{l}\text { Mean } \pm \text { SD } \\
(\mathbf{g} / \mathbf{l})\end{array}$ & $\boldsymbol{p}$ value \\
\hline \multirow{3}{*}{ Albumin } & Moderate & $36.33 \pm 3.89$ & \\
& Severe & $30.22 \pm 5.45$ & \\
alpha 1 & Critical & $22.92 \pm 4.07$ & \\
& Moderate & $3.35 \pm 0.87$ & 0.83 \\
alpha 2 & Severe & $3.54 \pm 1.19$ & \\
& Critical & $3.51 \pm 1.37$ & 0.66 \\
beta & Moderate & $11.32 \pm 2.08$ & \\
& Severe & $11.94 \pm 3.59$ & \\
gamma & Critical & $12.10 \pm 3.91$ & \\
& Moderate & $10.00 \pm 1.44$ & \\
& Severe & $8.87 \pm 1.73$ & 0.001 \\
\hline
\end{tabular}


Figure (1): comparison of SPE parameters between study groups

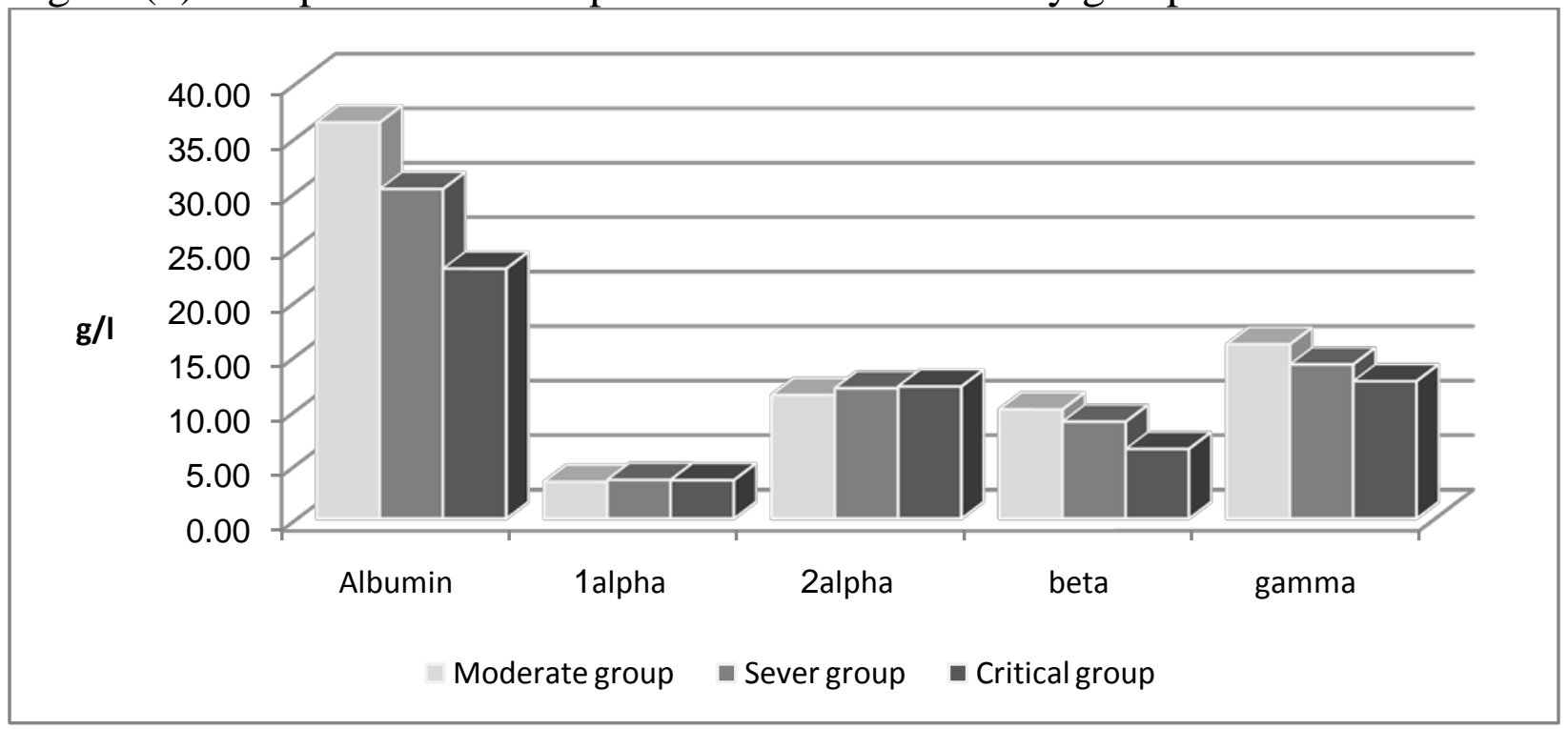

${ }_{1}(p=0.83)$ and $\alpha_{2}(p=0.66)$.

\section{Discussion}

In Albumin pattern, there was a direct relationship between low albumin and the severity of infection as shown in table (1) in a significant difference between groups themselves $(p<0.001)$, and these results were in agreement with other research, which showed that decreased albumin values (Hypoalbuminemia) were parallel to the increased severity of covid-19 infection [12].

The next pattern is known as Alpha 1 band. This band is constituted of two major proteins: alpha one antitrypsin and alpha 1acid glycoprotein. The following pattern was Alpha 2,that comprised of main proteins: Haptoglobin, alpha 2 macroglobulin and ceruloplasmin[13], All mentioned proteins in two previous bands, were considered acute phase proteins and these types of proteins are inflammation indicators that show substantial variations in serum concentration during the inflammatory response accompanied by SARS-CoV-2 [6]. Each band showed no significant difference in comparison with the severity of disease seen in table (1)\& figure (1).

The consequent pattern termed, Beta, consists of three major proteins: low density lipoprotein, transferrin and complement component [13].We found a significant difference in relation to severity $(\mathrm{p}<0.001)$ in table (1)\& figure (1), The amount of beta protein concentration reduced with developing severity. This change in this pattern might be related to the occurrence of hypolipidemia[14] or because of the 
depletion of a huge amount of complement associated with SARS-CoV-2 infection [15].

Finally, last pattern known as gamma, which involved gamma globulin of various antibody types [13], there was an inverted relation between gamma globulin contents and the severity of covid-19 with a significant difference $(\mathrm{p}=0.02)$ in table (1)\& figure (1). It is a well-known fact that a decrease in immunoglobulin progression leads to increases in infection, this result agree with [16].

\section{Conclusion}

In conclusion, we found an inverse relation in albumin, beta and gamma patterns with the severity of patients infected with SARS-CoV-2 virus.

\section{References}

[1] C. Huang et al., "Clinical features of patients infected with 2019 novel coronavirus in Wuhan, China," The Lancet, vol. 395, no. 10223, pp. 497-506, 2020, doi: https://doi.org/10.1016/S0140-6736(20)30183-5.

[2] L. A. Potempa, I. M. Rajab, P. C. Hart, J. Bordon, and R. Fernandez-Botran, "Insights into the use of C-reactive protein as a diagnostic index of disease severity in COVID-19 infections," The American journal of tropical medicine and hygiene, vol. 103, no. 2, pp. 561-563, 2020.

[3] C. Qin et al., "Dysregulation of Immune Response in Patients With Coronavirus 2019 (COVID-19) in Wuhan, China.," Clinical infectious diseases : an official publication of the Infectious Diseases Society of America, vol. 71, no. 15, pp. 762-768, Jul. 2020, doi: 10.1093/cid/ciaa248.

[4] C. Tóthová, X. Mihajlovičová, and O. Nagy, "The use of serum proteins in the laboratory diagnosis of health disorders in ruminants," Ruminants-The Husbandry, Economic and Health Aspects. London: IntechOpen Ltd, pp. 105-146, 2018.

[5] C. Tothova, O. Nagy, and G. Kovac, "Serum proteins and their diagnostic utility in veterinary medicine: a review,” Veterinární medicína, vol. 61, no. 9, pp. 475-496, 2016.

[6] L. Li and C. Chen, "Contribution of acute-phase reaction proteins to the diagnosis and treatment of 2019 novel coronavirus disease (COVID-19)," Epidemiology and infection, vol. 148, pp. e164-e164, Jul. 2020, doi: 10.1017/S095026882000165X.

[7] S. Ramanathan and C. N. Srinivas, "Serum Protein Electrophoresis and Its Clinical Applications," in Biochemical Testing-Clinical Correlation and Diagnosis, IntechOpen, 2019. 
[8] X. Liu et al., "Proteomics Analysis of Serum from COVID-19 Patients," ACS Omega, vol. 6, no. 11, pp. 7951-7958, Mar. 2021, doi: 10.1021/acsomega.1c00616.

[9] X. Hou et al., "Serum Protein Profiling Reveals a Landscape of Inflammation and Immune Signaling in Early-stage COVID-19 Infection," Molecular \& Cellular Proteomics, vol. 19, no. 11, pp. 1749-1759, 2020, doi: https://doi.org/10.1074/mcp.RP120.002128.

[10] "Clinical management Clinical management Living guidance COVID-19," no. January, 2021.

[11] "Helena Biosciences :: SAS-1plus / SAS-2." https://www.helenabiosciences.com/en/clinical-electrophoresis/gel/sas-1/ (accessed Mar. 23, 2021).

[12] Y. Zhang, L. Zheng, L. Liu, M. Zhao, J. Xiao, and Q. Zhao, "Liver impairment in COVID-19 patients: A retrospective analysis of 115 cases from a single centre in Wuhan city, China," Liver international, vol. 40, no. 9, pp. 20952103, 2020.

[13] J. R. Wiencek, S.-H. Duh, and R. H. Christenson, "Chapter 22 - Proteins: analysis and interpretation in serum, urine, and cerebrospinal fluid," W. Clarke and M. A. B. T.-C. P. in C. C. (Fourth E. Marzinke, Eds. Academic Press, 2020, pp. 365-390.

[14] X. Wei et al., "Hypolipidemia is associated with the severity of COVID-19," Journal of Clinical Lipidology, vol. 14, no. 3, pp. 297-304, 2020, doi: https://doi.org/10.1016/j.jacl.2020.04.008.

[15] A. Ghazavi, "Reduction of In ammatory C3 and C4 Complement Proteins in Severe COVID-19 Patients,” pp. 1-11.

[16] F. Husain-Syed et al., "Immunoglobulin deficiency as an indicator of disease severity in patients with COVID-19.," American journal of physiology. Lung cellular and molecular physiology, vol. 320, no. 4, pp. L590-L599, Apr. 2021, doi: 10.1152/ajplung.00359.2020. 